\title{
DE AGROVILA A NÓ LOGÍSTICO DO AGRONEGÓCIO NA AMAZÔNIA: O CASO DE MIRITITUBA, ITAITUBA, PARÁ
}

Resumo: A presente pesquisa tem como objetivo analisar as políticas públicas e coorporativas de logística do agronegócio da soja para viabilizar a exportação de commodity agrícola pelos portos do Arco Norte, com ênfase para o distrito de Miritituba, Itaituba, Pará e seus reflexos no lugar, face à implantação de Estações de Transbordo de Cargas (ETC) em Miritituba. A metodologia aplicada está amparada em uma pesquisa quantitativa e qualitativa, o que consistiu no levantamento documental, bibliográfico, utilizando a técnica de trabalho de campo com entrevistas de moradores e registro fotográfico, trata-se de um estudo de caso. Os principais resultados indicam que com a implantação de ETC em Miritituba, a partir de 2014, a localidade passou a ser objeto de uma série de transformações sócio - econômicas - territoriais.

Palavras-chave: Agronegócio. Logística. Portos. Arco Norte. Miritituba

\section{FROM AGRI-VILLAGE TO LOGISTIC KNOT CONCERNING AGRIBUSINESS IN THE AMAZON .THE CASE OF THE CITIES OF MIRITITUBA AND ITAITUBA IN PARÁ}

\begin{abstract}
The current research aims to analyze corporative and public policies regarding logistic of soybean agribusiness to enable the exportation of commodity agriculture by the ports of the North Arc, with emphasis on the districts of Miritituba and Itaituba in Pará and their reflexes in the place, in front of the implantation of Cargo Transshipment Station (ECT) in Miritituba. The methodology applied is based on a qualitative and quantitative research, which consisted of the bibliographic, document survey, using the field work technique through the application of interviews with residents and photographic register, it is about a study case. The main results indicate that with the ECT implementation in Miritituba from 2014, the place turned to be the object of a series of socio- territorial-economic transformations.
\end{abstract}

Keywords: Agribusiness. Logistics. Ports. North Arc. Miritituba

\section{DE AGROVILLA A NODO LOGÍSTICO DEL AGRONEGOCIO EN LA AMAZONIA: EL CASO DE MIRITITUBA, ITAITUBA, PARÁ.}

Resumen: La presente investigación tiene como objetivo analizar las políticas públicas y corporativas de logística del agronegocio de la soja para posibilitar la exportación de commodity agrícola en los puertos de Arco Norte, con énfasis para el distrito de Miritituba, Itaituba, Pará y sus reflejos en el lugar, delante de la implantación de Estaciones de Transbordo de Cargas (ETC) en Miritituba. La metodología aplicada está basada en una investigación cuantitativa y cualitativa, lo que consiste en el relevamiento bibliográfico, utilizando la técnica de trabajo de campo con entrevistas de moradores y registro fotográfico, constituyendo un estudio de caso. Los principales resultados indican que con la implantación de ETC en Miritituba, a partir de 2014, la localidad se volvió un objeto de una serie de transformaciones socio - económicas - territoriales.

\footnotetext{
1 Universidade Federal do Oeste do Pará, Instituto de Ciências da Sociedade, Santarém, Brasil. marcio.barros@ufopa.edu.br, https://orcid.org/0000-0001-5764-5692
} 
Palabras clave: Agronegocio. Logística. Puertos. Arco Norte. Miritituba.

\section{Introdução}

O território onde atualmente está localizado o distrito de Miritituba, Itaituba, Pará tem suas origens associado ao processo de ocupação territorial pela coroa portuguesa na Amazônia iniciada no século XVII com a fundação de Belém do Pará em 1616.

A ocupação do vale do rio Tapajós pelos colonizadores portugueses tem na figura de Pedro Teixeira uma centralidade, que por volta de 1626 percorreu trechos do rio Tapajós (REIS, 1993).

Itaituba surge de um aldeamento de índios para onde por volta de 1836, foi constituído um destacamento militar sendo enviado para o local o tenente Joaquim Caetano Correa, considerado o fundador da cidade (IBGE, 1957)

Em frente a cidade de Itaituba surge a localidade de Miritituba, habitada por colonizadores portugueses e índios Mundurukus. O mapa seguinte mostra a localização de Miritituba, no município de Itaituba, estado do Pará.




A partir da década de 1970 no contexto das políticas do Programa de Integração Nacional (PIN) foi construída a rodovia Transamazônica (BR 230). Naquela época a área onde atualmente encontra-se o distrito de Miritituba existia uma fazenda de propriedade de Tibiriçá Cunha, em cujo local foram instalados vários alojamentos de trabalhadores responsáveis pela construção desta rodovia.

Ao longo desta rodovia teve início um intenso processo de colonização dirigida, onde foram criados três Projetos Integrados de Colonização (PIC'S): PIC Altamira, PIC Itaituba e PIC Marabá (CARDOSO, MÜLLER, 1977; BARROS, 2011)

O PIC Itaituba teve sua primeira sede no distrito de Miritituba, onde foi instalada uma agrovila sob a gestão do Instituto Nacional de Colonização e Reforma Agrária (INCRA). (SUDAM, 1976). A partir de 2010 inicia os primeiros estudos visando à instalação de Estações de Transbordo de Cargas (ETC) no distrito de Miritituba. Atualmente existem quatro grandes ETC's de escoamento de grãos instalados em Miritituba, a saber: ETC da Bunge\Amaggi, ETC da Hidrovias do Brasil, ETC da Cianport e ETC da Cargill. A chegada destas instalações portuárias foi responsável, por uma série de dinâmicas sócio - econômicas - territoriais no distrito em análise.

O presente artigo está dividido em sete partes, incluindo a introdução e as considerações finais. $\mathrm{Na}$ introdução apresentamos uma descrição do contexto da ocupação de Miritituba. Na segunda parte intitulada "o avanço da fronteira agrícola e a logística do agronegócio", apresentamos uma breve contextualização teórica sobre "fronteira agrícola" e "logística". Na terceira parte que tem como título, "as políticas públicas para a integração territorial e colonização dirigida na Amazônia, uma ênfase no oeste do Pará", contextualiza-se as ações estatais relacionada a construção das rodovias Transamazônica (BR 230) e Cuiabá - Santarém (BR 163). Na quarta parte intitulada de "as políticas de estado e corporativa para viabilizar a criação de novas rotas de exportação de soja pela Amazônia e seus rebatimentos no oeste do Pará", discute-se as ações estatais e privadas para a exportação de soja pelos portos do Arco Norte. Na quinta parte denominada de "o sistema logístico das empresas de agronegócio instaladas em Miritituba, Pará", caracteriza-se as ações logísticas das empesas presentes em Miritituba. Na sexta parte intitulada de "as dinâmicas a partir da instalação de Estações de Transbordo de Cargas (ETC) em Miritituba, Itaituba, Pará", apresentamos os resultados da pesquisa empírica realizada em vila de Miritituba". Por fim são apresentados as considerações finais. 


\section{O avanço da fronteira agrícola e a logística do agronegócio}

A crise cambial de 1999 intensifica por parte do governo federal a ampliação de políticas públicas com o objetivo explícito de aumentar as exportações brasileiras e assim gerar saldos da balança comercial brasileira, fator que contribuiria para o pagamento da dívida externa brasileira. Este processo foi nomeado de imperativo da exportação por Milton Santos (1999) e de econômica do agronegócio por Guilherme Delgado (2012).

O imperativo da exportação, sugerido a todos os países como uma espécie de solução salvadora, é uma verdade ou apenas um mito? Afirma - se, com muita força, que os países que não exportam não têm presente nem futuro, sem explicar cabalmente porque (SANTOS, 2002, p.87)

A partir dos anos 2000 com o pacto do poder com os donos da terra (DELGADO, 2013) o Estado amplia o acesso ao crédito público para o financiamento do agronegócio no Brasil, neste sentido merece destaque o papel do Sistema Nacional de Crédito Rural (SNCR) que passou a viabilizar o financiamento do agronegócio. Com forte apóio do crédito rural para o setor, houve a expansão da fronteira agrícola para novas regiões como o Norte do Brasil. No entanto, a expansão da fronteira em direção ao Norte começou a encontrar serias dificuldades para a exportação pelos tradicionais portos de Santos (SP) e Paranaguá (PR).

No caso particular da soja, a constante expansão da produção para as áreas setentrionais do cerrado, distantes dos principais portos exportadores e com menores densidades de infraestruturas de transporte e armazenamento, tem criado importantes desafios para a logística de exportação. Sob forte pressão da mídia e dos representantes setoriais e com intuito de aumentar a denominada competitividade do agronegócio, o Estado brasileiro tem planejado e implantado sistemas de engenharia com o objetivo de conferir fluidez à produção agrícola moderna. O objetivo principal é a criação de sistemas de engenharia de transportes multimodais que viabilizem as exportações em direção ao Norte, utilizando-se dos portos das regiões Norte e Nordeste, o que permitiria encurtar a distância entre as áreas produtoras e os portos exportadores [...] (FREDERICO, 2014, p.2140)

O termo logística possui diversos significados dependendo da área de conhecimento que esteja sendo utilizado. No presente trabalho usamos a definição abaixo por levar em consideração a dimensão geográfica do emprego do termo logística.

Logística, na migração do sentido militar para o empresarial, tornou-se um termo escorregadio e polissêmico, empregado para designar variadas formas de prestação de serviços, condições gerais de produção, setor de atividade econômica, ramo de investimentos públicos entre outras. $\mathrm{Na}$ tentativa de compreender o termo em sua dimensão geográfica, propomos, por ora, defini-lo como o conjunto de competências infra-estruturais (transportes, armazéns, terminais intermodais, portos secos, centros de distribuição etc.), institucionais (normas, contratos de concessão, parcerias 
público privadas, agencias reguladoras setoriais, tributação) e estratégicas (conhecimento especializado detido por prestadores de serviços ou operadores logísticos) que reunidos num subespaço, podem conferir fluidez e competitividade aos agentes econômicos e aos circuitos espaciais produtivos trata-se da versão atual da circulação coorporativa (CASTILLO, 2007, p. 23)

A logística no período da globalização representa a possibilidade de maior relação entre pontos selecionados. Representa a conexão entre mercados cada vez mais integrados no atual período da globalização.

Ainda segundo Castillo (2011):

A logística torna-se, assim, a expressão de uma organização e de um uso do território, voltados, na linguagem corporativa (que também é da grande mídia), para a superação dos gargalos da circulação, para se evitar os "apagões" (portuárias, ferroviários, de armazenamento, etc.) e para se reduzir o "custo país" (CASTILLO, 2011, p.339)

Com relação aos modais de logística de transporte no território brasileiro o transporte hidroviário apresenta o menor custo no transporte no Brasil. No entanto, por questões históricas de opção pelo modelo rodoviário de transporte em nosso país, o frente rodoviário prevalece em detrimento do frete ferroviário e hidroviário, conforme mostra a afirmativa abaixo.

De maneira geral, o frete hidroviário é $36 \%$ mais econômico do que o frete ferroviário e este é cerca de $31 \%$ mais econômico do que o frete rodoviário. As rodovias teoricamente, deveriam ser utilizadas para distancias curtas (como vasos capilares ou linhas alimentadoras), uma vez que as hidrovias e as ferrovias são consideradas artérias principais ou linhas - tronco (CASTILLO, 2011, p.342)

No Brasil por questões políticas, que data desde a implantação da indústria automobilística, durante o governo de Juscelino Kubistchek (JK), onde foi implantado um modelo de transporte rodoviarista, desde então o país tem investido pouco nos modais de transporte como o ferroviário e o hidroviário.

No caso do transporte de cargas na Amazônia pelas características básicas da região, o transporte hidroviário apresenta bastante vantagens se comparados com os demais modais de transporte. Porém por falta de políticas para esse setor, o transporte hidroviário tem sido pouco utilizado no Brasil se comparado com o modal rodoviário. 
Até a primeira metade do século $X X$, a Amazônia recebeu pouca atenção do governo federal no que refere-se a execução de políticas públicas de desenvolvimento regional. É somente no governo de Getúlio Vargas em 1940, que a região amazônica passa a ser objeto de políticas de desenvolvimento regional, materializadas com a criação de diversas instituições federais nos estados amazônicos. O marco de redescoberta da Amazônia por parte do governo federal tem como referência o discurso do Rio Amazonas, pronunciado pelo presidente Getúlio Vargas em 10 de outubro de 1940, no teatro Amazonas, na cidade de Manaus, estado do Amazonas. Nos anos posteriores a este discurso durante 0 exercício de Getúlio Vargas na presidência da república, que termina em 1954, com seu suicídio, foram criados importantes instituições que possibilitaram a incorporação física, social, econômica e territorial da Amazônia ao Brasil, como o Banco de Crédito da Borracha (BCB), o Instituto Agronômico do Norte (IAN), os Territórios Federais do Guaporé, Amapá e Rio Branco, a Superintendência do Plano de Valorização Econômica da Amazônia (SPVEA), e o Instituto Nacional de Pesquisas da Amazônia (INPA). (SUDAM, 1968).

Em seu discurso em Manaus, o então presidente Getúlio Vargas destacou que: "Vim para observar, de perto, as condições de realização do plano de reerguimento da Amazônia. Todo o Brasil tem os olhos voltados para o Norte, com o desejo patriótico de auxiliar o surto do seu desenvolvimento" (SUDAM, 1968, p. 10).

No entanto foi somente com o início dos governos militares (1964 -1985) que foi elaborado e executado um conjunto de ações públicas que resultaram na integração física, econômica, social e territorial da Amazônia ao Brasil. O marco das ações do governo federal durante o regime militar ocorre em 1966, durante o discurso do Amapá, proferido pelo presidente Marechal Humberto Castelo Branco em Macapá, no então Território Federal do Amapá em 1ํ de setembro de 1966. Este discurso marca o lançamento da operação Amazônia, que resultaria em um conjunto de ações federais que visavam a integração territorial e econômica da Amazônia ao Brasil.

Neste discurso realizado no Amapá, em 1966, o presidente Castelo Branco afirma:

Daí estar colocado em primeiro plano das preocupações do governo o desenvolvimento econômico da região, a sua ocupação racional, o fortalecimento das áreas de fronteira e a integração do espaço amazônico no todo nacional. Com esse propósito, estuda-se completa reformulação da política nacional até agora seguida e que deverá ser mudada de acordo com a experiência dolorosamente acumulada. Aliás, aos que acompanham a ação do governo tornou-se tão evidente o progresso da região que, para 
envolver as várias medidas a serem adotadas, já criaram até a expressão "operação Amazônia". Antecipam-se, assim, de pouco, a série de procidências e iniciativas com que o governo pretende propiciar condições inteiramente novas e vigorosas para transformar a economia da Amazônia (SUDAM, 1972, p. 16)

As primeiras medidas da operação Amazônia, em 1966 resultaram na transformação do Banco de Crédito da Borracha (BCA) em Banco da Amazônia (BASA) e da Superintendência do Plano de Valorização Econômica da Amazônia (SPVEA) em Superintendência de Desenvolvimento da Amazônia (SUDAM). Desde então as principais políticas federais voltadas para a Amazônia tem sido direcionadas para a ocupação territorial e econômica da região.

Uma das políticas federais voltadas para a ocupação produtiva da região foi o Programa de Pólos Agropecuários e Agrominerais da Amazônia (POLAMAZONIA), criado mediante o decreto ํo 74.607 de 25 de setembro de 1974. Este programa estava baseado na seleção de 15 polos selecionadas na Amazônia que receberam um conjunto de ações de políticas públicas. Um dos polo selecionados do POLOAMAZONIA foi o polo Tapajós, que em 1976 abrangia áreas dos municípios de Santarém, Aveiro e Itaituba (SUDAM, 1976)

$\mathrm{Na}$ área de atuação do Polamazônia Tapajós, houve a implantação de experiências da colonização dirigida ao longo da rodovia Transamazônica. $\mathrm{Na}$ concepção do governo da época era preciso "ocupar espaços vazios na Amazônia" atribuindo desta forma uma valorização das terras da região.

Segundo Cardoso e Müller, (1977, p.141), "A colonização dirigida aparece, portanto, como um esforço consciente, não apenas para ocupar os vazios amazônicos e valorizar as terras, mais como uma alternativa para a "pressão" demográfica em certas áreas do país"

A ocupação do território do município de Itaituba, foi completamente transformado pelas políticas de integração nacional no início da década de 1970, com a abertura das rodovias Transamazônica (BR 230) e Cuiabá - Santarém (BR 163) que cortam o território municipal.

Segundo o Caderno do Polamazônia Tapajós, sobre o PIC-Itaituba, o projeto foi iniciado com 30 famílias remanescente das empresas construtoras da rodovia Transamazônica em julho de 1972. O documento informa que estes assentados foram regularizados em julho e que em agosto inicia o assentamento de novas famílias de assentados. A localização espacial dos núcleos urbanos do projeto são; a) em Miritituba, em frente a Itaituba; b) no Km 80, vindo de Itaituba para Rurópolis; c) no 47, indo de Rurópolis para Altamira; d) no Km 71, indo de Rurópolis para 
Altamira; e) no Km 86, da Cuiabá - Santarém, sentido Rurópolis/Santarém. (SUDAM, 1976)

No trecho paraense da rodovia Transamazônica foram criados três Projetos Integrados de Colonização (PIC'S): PIC Altamira, PIC Itaituba e PIC Marabá ao longo da BR 230. O PIC Altamira foi o que mais recebeu assentados, o PIC Itaituba recebeu a menor quantidade de assentados (CARDOSO; MÜLLER, 1977)

Dados da colonização dirigida do Programa de Integração Nacional (PIN) para o trecho paraense da rodovia Transamazônica indicava que para o PIC Altamira em 1972 foram planejados o assentamento de 3.000 famílias e executados 2.550, restando a executar 450 famílias em 1972. No PIC Marabá foi projetado o assentamento de 1.000 famílias e executado 600 famílias e a executar 400 para 0 ano de 1972. No caso do PIC Itaituba foi previsto assentar 500 famílias, sendo executado a totalidade do que foi projetado para este ano de 1972, conforme podemos verificar no quadro seguinte.

Quadro 01: Projetos de apoio ao PIN no trecho paraense da rodovia transamazônica

\begin{tabular}{|l|l|l|l|l|}
\hline \multirow{2}{*}{ Projetos } & \multirow{2}{*}{ Localização } & \multicolumn{3}{|c|}{ Assentamento de famílias } \\
\cline { 3 - 5 } & & $\begin{array}{l}\text { Projetado (1972) } \\
\text { no }\end{array}$ & $\begin{array}{l}\text { Executado } \\
\text { no }\end{array}$ & $\begin{array}{l}\text { A executar (1972) } \\
\text { no }\end{array}$ \\
\hline Altamira & Pará & 3.000 & 2.550 & 450 \\
\hline Marabá & Pará & 1.000 & 600 & 400 \\
\hline Itaituba & Pará & 500 & 500 & - \\
\hline
\end{tabular}

Fonte: Colonização da Amazônia, PIN, Brasília, 1972, p.32

Nota: Quadro transcrito de Fernando Henrique Cardoso e Geraldo Mülller, Amazônia: expansão do capitalismo. Brasiliense - Cebrap. São Paulo, 1977, p. 144. Com modificação do autor.

Em reportagem publicada por Ferrando Morais pelo Jornal da Tarde em 27\09\1974 revelou novos dados de assentamentos realizados ao longo do trecho paraense da Transamazônica para o ano de 1974. No caso do PIC Itaituba, até setembro de 1974 foram assentados 1.700 famílias, o que correspondia 11.900 pessoas, distribuídas em 200 casas construídas pelo INCRA, como podemos constatar no quadro seguinte que apresenta também dados para os PIC de Altamira e Marabá.

Quadro 02: Colonização da transamazônica (até setembro de 1974)

\begin{tabular}{|l|l|l|l|l|}
\hline Projetos em & Marabá & Altamira & Itaituba & Totais \\
\hline Famílias & 1.350 & 2.036 & 1.700 & 6.080 \\
\hline
\end{tabular}




\begin{tabular}{|l|l|l|l|l|}
\hline Pessoas & 9.450 & 21.250 & 11.900 & 42.600 \\
\hline Casas & 314 & 408 & 200 & \\
\hline Famílias sem casa & & & & 5.160 \\
\hline Pessoas sem casa & & & & 36.120 \\
\hline
\end{tabular}

Fonte: Jornal da Tarde, 27/09/1974; dados publicados em reportagem de Fernando Morais, "De volta à transamazônica".

Nota: Quadro transcrito de Fernando Henrique Cardoso e Geraldo Müller, Amazônia: expansão do capitalismo. Brasiliense - Cebrap. São Paulo, 1977, p. 198.

Quanto a origem das famílias dos colonos assentados nos projetos de colonização dirigida nos três PIC's do trecho paraense da rodovia Transamazônica em 1973, os dados mostram que 1.004 tem origem no Nordeste, 859 no Meio Norte, 794 no Norte, 254 no Sul, 424 no Oeste e 215 no Sudeste. No caso do PIC Itaituba, a origem dos 571 colonos assentados em 1973 foram: 262 do Meio Norte, 159 do Oeste, 114 do Norte, 109 do Sul, 71 do Nordeste e 34 do Sudeste, conforme podemos constatar no quadro abaixo.

Quadro 03: Área de origem das famílias de colonos em núcleos da Transamazônica - 1973

\begin{tabular}{|l|l|l|l|l|l|l|l|}
\hline \multirow{2}{*}{ Zona } & \multirow{2}{*}{$\begin{array}{l}\text { № } \\
\text { colonos }\end{array}$} & \multicolumn{7}{|c|}{ Origem dos colonos } \\
\cline { 4 - 9 } & 2.559 & 543 & 147 & 335 & 862 & 566 & 106 \\
\hline Altamira & 571 & 109 & 34 & 262 & 71 & 114 & 159 \\
\hline Itaituba & 643 & 2 & 34 & 262 & 71 & 114 & 159 \\
\hline $\begin{array}{l}\text { Marabá } \\
\text { (Itupiranga) }\end{array}$ & 643 Norte & Nordeste & Norte & Oeste \\
\hline
\end{tabular}

Fonte: INCRA, 1973. Cf. J.M.G. Kleinpenning, The integration and colonization of the Brazilian Portion of the Amazon Basis, citado, p. 119.

Nota: Quadro transcrito de Otavio lanni. Colonização e contra - reforma agrária na Amazônia. Petrópolis: Vozes, 1979.

No PIC de Itaituba foi instalada a agrovila de Miritituba, com a criação de lotes urbanos, escritório do INCRA, armazém da extinta Companhia Brasileira de Armazenamento (CIBRAZEM), que era responsável pela compra da produção agrícola dos assentados nesta agrovila. Em Miritituba foi implantado uma agrovila com residências para os assentados. As casas são todas padronizadas como mostra a figura 01 .

A agrovila é a menor unidade urbana, essencialmente residencial, para rurícolas e tem por objetivo integrar socialmente o meio rural, oferecendo condições sociais as famílias dos que trabalham nos campos, a fim de que possam viver em comunidade e formar uma sociedade em moldes civilizados. Os rurícolas (proprietários de lotes rurais econômicos e empregados rurais), neste sistema urbano-rural, possuirão um lote rural de 100 há, onde exercerão suas atividades econômicas agropastoris e um lote urbano, residencial, de 1.500 a 3.000 metros quadrados, nas agrovilas, onde poderão fazer pequeno pomar, pequena horta, criar galinhas e 
animais de pequeno porte para uso doméstico, com a finalidade de complementar suas necessidades de manutenção (INCRA, 1972, p. 67).

Miritituba, está localizada em frente a cidade de Itaituba, na margem direita do rio Tapajós. Nesta agrovila houve a instalação de uma unidade do Departamento Nacional Estradas e Rodagens (DNER) quando da construção da rodovia Transamazônica em 1972. No local foram instalados um escritório do INCRA, instalações do DNER, da Companhia do 8 Batalhão de Engenharia do Exército, Terminal de Combustível da Petrobrás (diesel e gasolina) e do Porto da Companhia Docas do Pará (SUDAM, 1978)

\section{Miritituba}

Figura 01: Lotes urbanos residenciais construídos pelo INCRA em

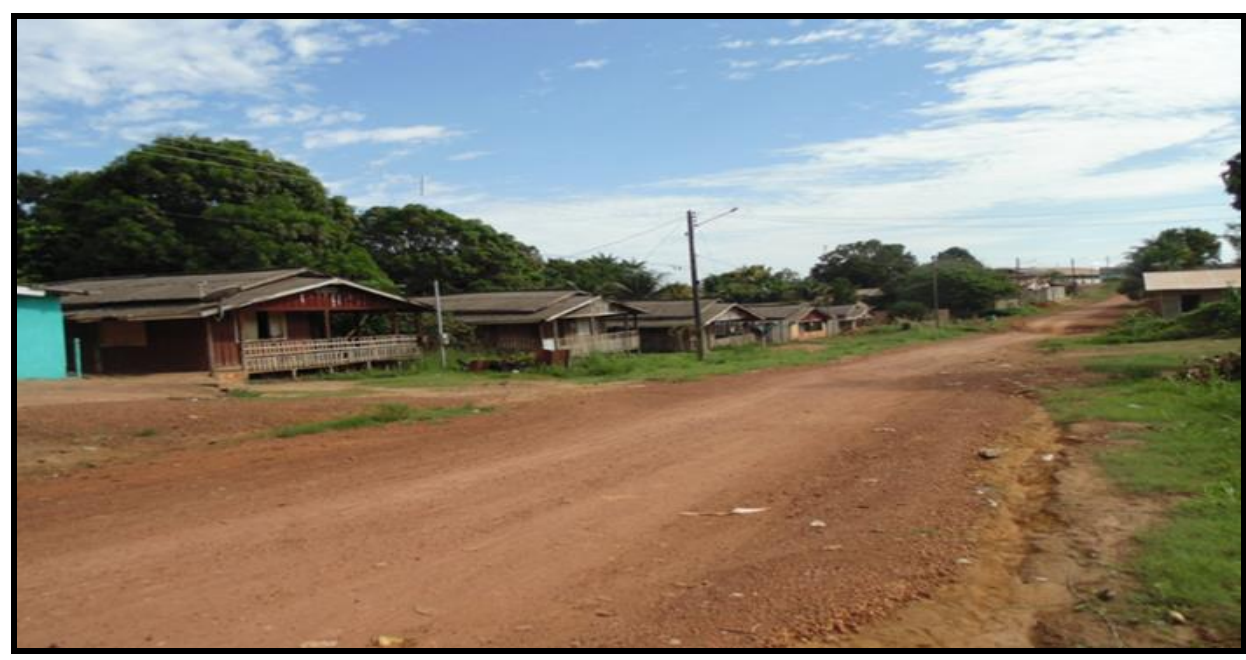

Foto: Márcio Benassuly, 2018.

Com a criação do III Programa Nacional de Desenvolvimento (III PND) a política de colonização dirigida foi sendo abandonada pelo governo federal que passou a incentivar por meio de incentivos fiscais da Superintendência de Desenvolvimento da Amazônia (SUDAM) a atração empresarial nacional e internacional, principalmente voltado para a pecuária e a exploração madeireira. Neste novo contexto, empreendimentos empresariais ligados a pecuária e exploração madeireira começam a serem instalados em Miritituba e seu entorno.

Com o avanço do asfaltamento da BR 163 nos anos 2000, aprovação da lei de portos em 2013 e a expansão da fronteira agrícola de soja para o Norte passa a haver uma forte pressão pela exportação da produção agrícola do Mato Grasso, principal produtor de grãos do Brasil, pelos portos do Arco Norte, localizados acima do paralelo 16 para a instalação de Terminais de Uso Privado (TUP) de empresas do agronegócio em Miritituba. 
O escoamento da produção agrícola do Mato Grosso pelos portos do Arco Norte representam a redução de custos em relação aos tradicionais portos de exportação de Santos (SP) e Paranaguá (PR).

\section{As políticas de estado e corporativa para viabilizar a criação de novas rotas de exportação de soja pela Amazônia e seus rebatimentos no oeste do Pará}

Com a eleição de Fernando Henrique Cardoso (FHC) para a presidência da república, teve início a uma série de ações que foram tomadas para viabilizar a construção de um conjunto de infraestrutura que pudesse permitir a exportação da soja pelos portos da região amazônica. Durante os dois mandados de FHC foram inseridos nos dois Planos Plurianuais (PPA) diversas ações com este propósito. No primeiro mandato, foi elaborado o Programa Brasil em Ação que previa a implantação de um conjunto de hidrovias na bacia amazônica. As hidrovias previstas foram a do rio Madeira no trecho entre Porto Velho (RO) e Manaus (AM) e dos rios Tocantins e Araguaia. Este programa previa o asfaltamento de trechos de diversas rodovias federais na região como a BR 163, BR 364 e BR 164 (OLIVEIRA, 2006).

No segundo mandato de FHC tem início o Programa Avança Brasil que procurou dar sequências nas ações estabelecidas durante o Programa Brasil em Ação para o setor de infraestrutura para a Amazônia. Neste programa foi prevista a viabilização da hidrovia Teles Pires e Tapajós que não chegou a sair do papel. Estes programas transformavam a Amazônia em eixos de desenvolvimento. A viabilização de partes destes projetos de logísticas na região resultariam na transformação da infraestrutura de logística até então empregada na Amazônia. Estas ações estatais de logística de transporte na região iniciadas ou concluídas resultam na movimentação de grandes empresas do setor de agronegócio da soja, que começaram a buscar novas rotas para exportação da soja produzida no CentroOeste tendo em vista a redução dos custos da produção (OLIVEIRA, 2006).

O grupo Amaggi, pertencente a André Maggi, pai do ex-governador de Mato Grosso, Blairo Maggi, foi pioneiro na abertura de uma nova rota de exportação em direção a Amazônia em 1997. A escolha do grupo foi o corredor noroeste, utilizando a hidrovia Madeira-Amazonas, onde em Itacoatiara (AM) foi construído as instalações do Terminal Graneleiro de Itacoatiara. Esta foi a primeira rota para exportação de soja operada por uma empresa em direção a Amazônia. Nesta rota a produção de grãos provenientes de Mato Grosso são transportado até Porto Velho (RO) de caminhões, onde neste local existe um porto que realiza o transbordo para 
barcaças que segue pelo rio Madeira até Itacoatiara, onde finalmente são transportados para grandes navios que seguem para os principais mercados consumidores.

A segunda rota criada para exportação de soja pelos portos da Amazônia foi inaugurada pela Cargill em 2003 em Santarém (PA). A empresa em 1999 assinou um contrato com a Companhia Docas do Pará (CDP), para a concessão para a instalação do porto da empresa em Santarém. Em 2000 a Cargill realizou a implantação do preço portuária da soja, atraindo dezenas de produtores, principalmente de Mato Grosso para o planalto santareno, que é atualmente constituído pelos municípios de Santarém, Belterra e Mojuí dos Campos (BARROS, 2018)

A terceira rota criada para exportação de soja pelos portos da Amazônia foi inaugura em 2014 pela Bunge em Barcarena (PA), que realizou um investimentos de R\$ 700 milhões para a criação do Complexo Portuário Miritituba - Barcarena, ligando a Estação de Transbordo em Miritituba, em Itaituba ao Terminal Portuário Fronteira Norte (Terfron) em Vila do Conde, Barcarena (ESTADO DE SÃO PAULO, 25\04\2014).

Nesta rota de escoamento a soja sai de municípios do norte de Mato Grosso, como Sinop de caminhão e segue pela BR 163 até Miritituba (PA) percorrendo 1.100 $\mathrm{km}$. Ao chegar a Miritituba a soja é colocada em barcaças que percorrerão o rio Tapajós e o estreito de Breves até chegar ao porto de Vila do Conde, em Barcarena (PA). Este percurso é de $1.000 \mathrm{~km}$ e dura três dias. Em Vila do Conde foi construído o Terminal Fronteira Norte (Terfron) onde a carga é armazenada para posterior embarque em navios graneleiros, de onde segue para os mercados da Europa e Ásia. Cada barcaça transporta cerca de 2.000 toneladas de grãos o que equivale a 50 caminhões (FOLHA DE SÃO PAULO, 25/04/2014).

Esta nova rota de escoamento de soja aberta pela Bunge foi oficialmente inaugurada em 24/04/2015 no porto de Vila do Conde em Barcarena, reunindo o ato escalão do governo federal e de empresas de agronegócio interessadas na exploração da nova rota de escoamento de grãos.

A criação desta rota de escoamento aberta pela iniciativa da Bunge, fez com que outras empresas do setor manifestassem interesses em explorar esta rota. Desta forma empresas como Hidrovias do Brasil, Cianport, Cargill além da Amaggi que exporta parte de sua produção em associação coma a Bunge já estão operando em Miritituba através de Estações de Transbordo de Cargas (ETC). 
A quarta rota criada para exportação de soja pelos portos da Amazônia, foi criada pela Cianport em 2016 entre Miritituba (PA) a Santana (AP). A empresa em 2016 finalizou a construção da Estação de Transbordo de Miritituba de onde a carga de grãos é transportada por barcaças para o Terminal Portuário de Santana, no Amapá.

As condições logísticas com o avanço do asfaltamento de trechos da BR 163 durante os governos FHC e LULA, estimularam grandes empresas em realizarem investimentos em Miritituba e as condições da revisão do marco jurídico do setor portuário com a aprovação da lei 12.815\2013 (lei de portos), estimularam o setor do agronegócio da soja a realizarem investimentos em Miritituba, criando desta forma um novo nó da logística rodoviário-hidroviário na Amazônia. A transformação na paisagem na área onde foram instaladas as Estações de Transbordo de Cargas (ETC) das empresas em Miritituba foram intensas.

A presença de Estações de Transbordo de Cargas em operação ou planejadas em Miritituba (Itaituba) e Santarenzinho (Rurópolis) tem transformado o rio Tapajós no novo Mississipi brasileiro segundo operadores da logística do agronegócio no Brasil. Além das empresas já instaladas em Miritituba com Estações de Transbordo de Cargas (Bunge\Amaggi, Hidrovias do Brasil, Cianport e Cargill) as empresas Unirios Rodofluvial e Logística Ltda. (ETC Unirios) e Porto Chibatão (ETC Chibatão) possuem projetos em andamento de construção de Estações de Transbordo de Cargas na localidade.

No distrito de Santarenzinho, município de Rurópolis, as empresas, Odebrecht (ETC Santarenzinho), Louis Dreyfus Company (Terminal LDC Tapajós), Bertolini (ETC Rurópolis), Cianport (ETC Tapajós) e Amaggi (ETC Amaggi) possuem projetos para instalação de ETC no local.

Segundo dados do Ministério dos Transportes (2017), sobre os investimentos em portos no Brasil, as três empresas com Estações de Transbordo de Cargas em Miritituba apresentaram as seguintes informações quando da realização do Contrato de Adesão formalizada junto ao governo federal, para a construção destas instalações portuárias. A Bunge foi a primeira empresa a assinar o Contrato de Adesão 13\2014 com a Secretaria Especial de Portos (SEP), da presidência da república, em 27\03\2014. Neste contrato a estimativa da empresa de movimentação de cargas (granel sólido) era de 3.500 .000 t/a e um investimento de $R \$$ 50.505.000,00 no projeto. A Hidrovias do Brasil foi a segunda a assinar o Contrato de Adesão 19l2014 com a SEP, assinado no dia 30l06\2014. A empresa previa a 
movimentação de 4.400 .000 t/a e um investimento de $\mathrm{R} \$ 200.000 .000,00$ no projeto no Tapajós.

A terceira empresa com Contrato de Adesão $20 \backslash 2014$ com a SEP foi a Cianport, assinado no dia 05\08\2014. A previsão da empresa era transportar 3.528.000 t/a e um investimento de $R \$ 43.869 .000,00$ no projeto. Os dados do Ministério dos Transportes, não informa os valores de investimentos para a empresa Cargill utilizados na construção do projeto em Miritituba.

Quadro 04: Investimentos de empresas que operam Estações de Transbordo de Cargas em Miritituba, Pará

\begin{tabular}{|c|c|c|c|c|c|}
\hline Empresa & Instalação & $\begin{array}{l}\text { Instrumento } \\
\text { de outorga }\end{array}$ & $\begin{array}{l}\text { Perfil } \\
\text { da } \\
\text { carga }\end{array}$ & $\begin{array}{l}\text { Estimativa de } \\
\text { movimentação }\end{array}$ & $\begin{array}{l}\text { Valor de } \\
\text { investimento }\end{array}$ \\
\hline $\begin{array}{l}\text { Bunge } \\
\text { Alimentos } \\
\text { S/A }\end{array}$ & $\begin{array}{l}\text { ETC } \\
\text { Miritituba }\end{array}$ & $\begin{array}{l}\text { Contrato de } \\
\text { Adesão } \\
\text { 13/2014 - } \\
\text { SEP/PR }\end{array}$ & $\begin{array}{l}\text { Granel } \\
\text { sólido }\end{array}$ & $3.5000 .000 t / a$ & $\begin{array}{l}\mathrm{R} \$ \\
50.505 .000,00\end{array}$ \\
\hline $\begin{array}{l}\text { Hidrovias } \\
\text { do Brasil } \\
\text { S/A }\end{array}$ & $\begin{array}{l}\text { ETC } \\
\text { Tapajós }\end{array}$ & $\begin{array}{l}\text { Contrato de } \\
\text { Adesão } \\
\text { 19/2014 - } \\
\text { SEP/PR }\end{array}$ & $\begin{array}{l}\text { Granel } \\
\text { sólido }\end{array}$ & $4.400 .000 \mathrm{t} / \mathrm{a}$ & $\begin{array}{l}R \$ \\
200.000 .000,00\end{array}$ \\
\hline $\begin{array}{l}\text { Cianport - } \\
\text { Companhia } \\
\text { Norte de } \\
\text { Navegação } \\
\text { e Portos }\end{array}$ & $\begin{array}{l}\text { ETC } \\
\text { Itaituba }\end{array}$ & $\begin{array}{l}\text { Contrato de } \\
\text { Adesão } \\
20 / 2014 \text { - } \\
\text { SEP/PR }\end{array}$ & $\begin{array}{l}\text { Granel } \\
\text { sólido }\end{array}$ & $3.528 .000 \mathrm{t} / \mathrm{a}$ & $\begin{array}{l}\mathrm{R} \$ \\
43.869 .000,00\end{array}$ \\
\hline
\end{tabular}

Fonte: Ministério dos Transportes, 2018. Organizado e modificado pelo autor.

Os dados do quadro acima refletem a importância de Miritituba, como importante nó logístico do agronegócio de soja, responsável pela conexão do transporte de cargas de grãos pela estrada (rodoviário) - rio (hidroviário). O valor dos investimentos das três empresas (Bunge, Hidrovias do Brasil e Cianport) totalizou $\mathrm{R} \$ 294.374 .000,00$ como podemos verificar no quadro acima.

O mapa seguinte mostra a localização das Estações de Transbordo de Cargas em Miritituba em 2018. 


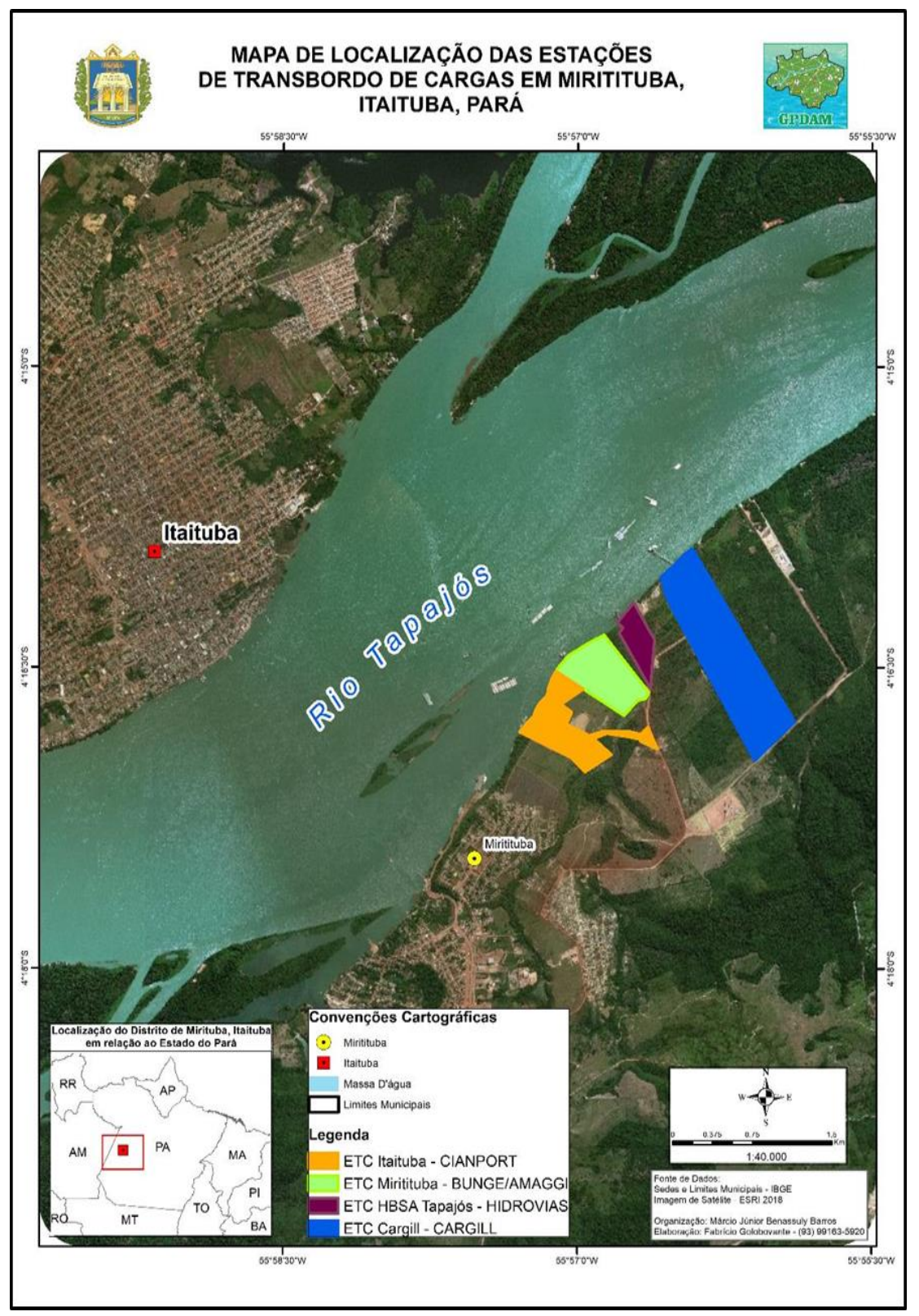

O sistema logístico das empresas de agronegócio instaladas em Miritituba, Pará

Bunge. É uma empresa norte-americana que tem sua sede em Nova York. A empresa atua no Brasil a mais de 100 anos, sendo a maior processadora de soja e trigo do país, líder no segmento de óleos vegetais, farinha de trigo e pré - misturas para panificação, além de ser a maior exportadora de agronegócio. Em 2016, possuía 100 unidades no Brasil, atuando em 17 estados e no Distrito Federal e possuía 17 mil colaboradores, transportando neste ano cerca de 35 milhões de toneladas de grãos no país. A empresa foi pioneira na abertura de nova rota de soja, realizando a conexão estrada, pela BR 163 a hidrovia Tapajós-Amazonas, ligando 
Miritituba ao Porto de Vila do Conde no município paraense de Barcarena (BUNGE, 2017)

A Estação de Transbordo de Cargas (ETC Miritituba) visa o escoamento de grãos e farelo de soja provenientes de produtores do norte do Mato Grosso que chegam a estação pela BR 163 por caminhões. Neste local a carga é transportada em barcaças que seguem para o Terminal Graneleiro de Barcarena onde será embarcada em grandes navios que seguem para os principais mercados consumidores globais.

Em 2016 a empresa firmou parceria com o grupo Amaggi para escoamento de grãos pela hidrovia Tapajós-Amazonas, mediante o compartilhamento das instalações da Estação de Transbordo de Miritituba e do Terminal Portuário de Barcarena (BUNGE, 2016)

Para realizar o transporte de Miritituba para Barcarena a Bunge realizou uma parceria mediante uma Joint Venture de transporte fluvial com a Amaggi, que resultou na criação da Navegações Unidas Tapajós Ltda. (Unitapajós) com a construção de 90 barcaças e 05 empurradores e com investimentos de $R \$ 300$ milhões (VALOR ECONÔMICO, 25\0412014)

Segundo dados do Anuário Estatístico Aquaviário², disponibilizado no site da Agência Nacional de Transporte Aquaviário (ANTAQ) em 2017 a Estação de Transbordo de Cargas em Miritituba da Bunge, movimentou cerca de 1.923.913 toneladas. Conforme podemos verificar no gráfico seguinte, que apresenta a evolução de cargas dos doze meses de 2017. O menor volume transportado ocorreu no mês de janeiro com 71.847 toneladas, por sua vez o maior volume transportado correu no mês de setembro com um volume de 274.027 toneladas transportado por Miritituba. O gráfico a seguir mostra demais meses para o ano de 2017.

${ }^{2}$ Disponível em: http://web.antaq.gov.br/Anuario/ . Acessado em 1010112019. 
Gráfico 01: Evolução da carga transportada (grãos e farelo de soja) pela Bunge em Miritituba, Pará, em 2017 em toneladas.

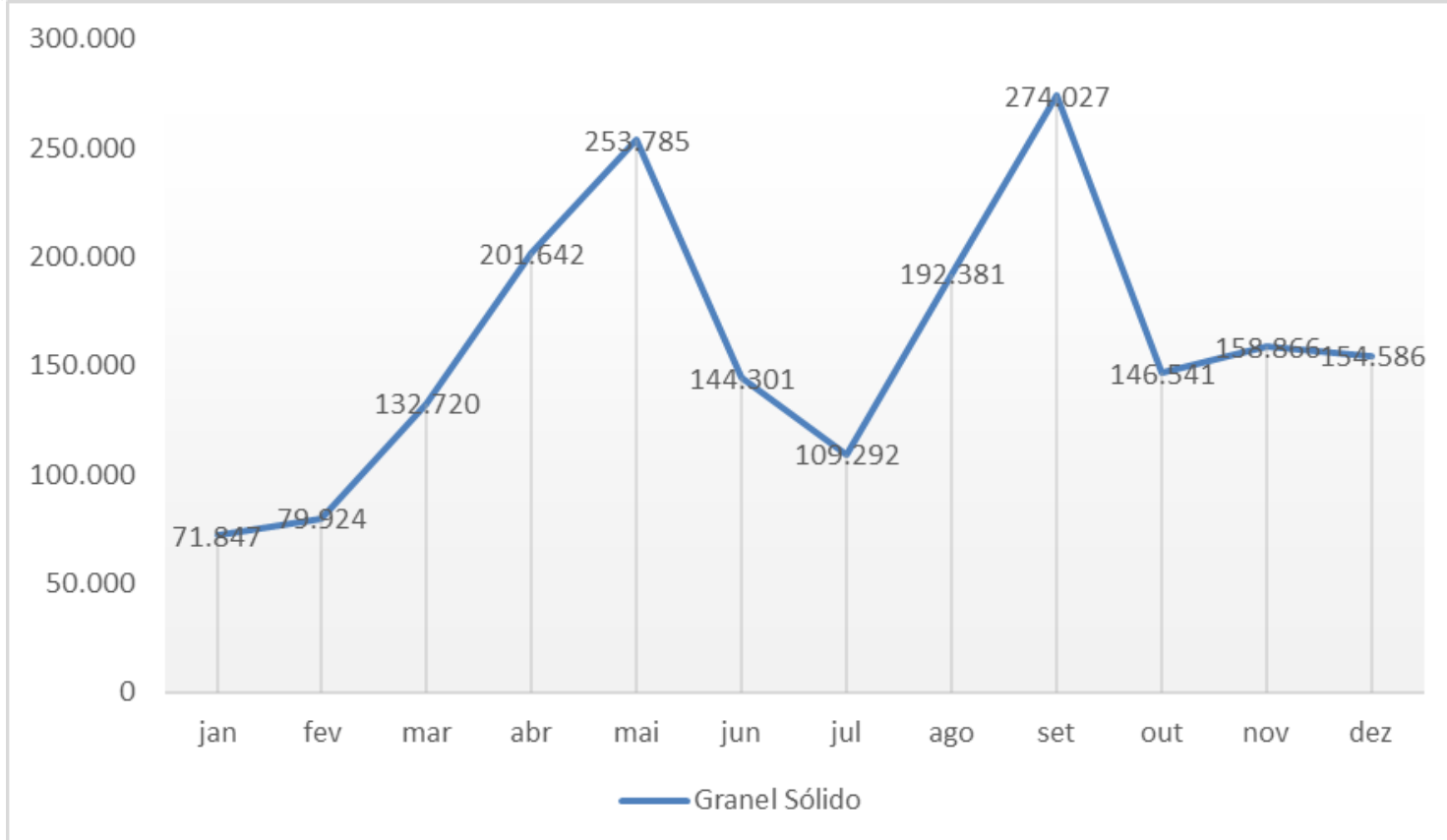

Fonte: Anuário Estatístico Aquaviário. 2019. Organizado pelo autor.

Amaggi. A empresa foi fundada em 1977 em São Miguel do Iguaçu, Paraná, em 1979 realiza a aquisição da primeira propriedade no estado de Mato Grosso, no município de Itiquira. Em 1997 a empresa foi pioneira ao iniciar o transporte de grãos em direção a Amazônia, mediante atividade de Porto Velho (RO) e Itacoatiara (AM) onde mantem instalações portuárias. Em 2002 tem início as operações de esmagamento de grãos em Itacoatiara (AM). Em 2014 a empresa realiza o primeiro transporte de grãos pelo corredor hidroviário Tapajós-Amazonas, dando início a uma parceria estratégica com a multinacional Bunge pelo compartilhamento das instalações da Estação de Transbordo de Miritituba (PA) e mediante a formação da Unitapajós. Em 2016 a empresa fez a aquisição de 50\% das Estação de Transbordo de Miritituba e do Terminal Portuário de Barcarena da Bunge (AMAGGI, 2017).

A empresa opera em dois corredores na Amazônia. O primeiro é o corredor Madeira e o segundo é o corredor Tapajós.

Corredor Madeira. Os grãos são transportados por caminhões até Porto Velho (RO) onde é realizado transbordo para barcaças que seguem pelo rio Madeira até o Porto Graneleiro de Itacoatiara (AM) de onde seguem para o mercado consumidor em grandes navios. Em 2016 a empresa possuía uma frota operando no corredor Madeira de 157 barcaças graneleiras, 20 empurradores e 3 empurradores em 
construção, que transportaram neste ano 3,7 milhões de toneladas de grãos. Opera este corredor com capital próprio (AMAGGI, 2017).

Corredor Tapajós. A empresa opera mediante uma Joint Venture com a Bunge o transporte hidroviário de grãos entre Miritituba - Barcarena mediante parceria firmada através da Unitapajós.

A empresa possuía em 2016 uma frota operando no corredor Tapajós de 90 barcaças graneleiras, 8 empurradores e 1 empurrador em construção, que transportaram neste ano 1,6 milhões de toneladas de grãos. Opera este corredor em parceria com a Bunge Alimentos (AMAGGI, 2017).

Cargill. Empresa americana fundada em 1865, tem sua sede global em Minneapolis, Minesota, Estados Unidos. Opera em 70 países, tem 150 mil funcionários no mundo. É a maior empresa de capital privado do mundo. Atua no Brasil desde 1965, com sua sede em São Paulo, possui no Brasil 22 fabricas e 05 terminais portuários (CARGILL, 2016).

A Estação de Transbordo de Cargas (ETC Cargill) localizada em Miritituba tem como objetivo o transporte de grãos da região de influência da BR 163 (MT-PA) até o terminal da empresa em Santarém.

Este transporte de grãos das regiões produtoras do norte do Mato Grasso ocorre de caminhões pela BR 163 até Miritituba de onde seguem por barcaças pela hidrovia Tapajós - Amazonas até o terminal da Cargill em Santarém. Neste local a carga será embarcada em navios com destino aos mercados mundiais consumidores.

Em 2015, o terminal de Santarém passou por uma ampliação que elevou sua capacidade de transporte para cinco milhões de toneladas. Em 2016 a empresa iniciou a operação da Estação de Transbordo de Miritituba (CARGILL, 2017)

Hidrovias do Brasiß3. A empresa foi criada em 2010 com o objetivo de promover soluções logísticas integradas na América Latina no setor de transporte hidroviário. A empresa atua em dois corredores logísticos: o corredor logístico norte e o corredor logístico sul.

O Corredor Logístico Norte. Visa atender a demanda de transporte de grãos e farelo de soja da região Centro - Oeste para os portos do Arco Norte. A empresa possui uma Estação de Transbordo de Cargas (ETC) em Miritituba, Itaituba, Pará e um Terminal de Uso Privado (TUP), no porto de Vila do Conde, Barcarena, Pará.

\footnotetext{
${ }^{3}$ Dados retirados do site da empresa: http://hbsa.com.br/empresa. Acessado em 25\0112019.
} 
A Estação de Transbordo de Cargas de Miritituba (ETC Miritituba) recebe a carga de grãos que chegam no local por caminhões que é posteriormente carregado em barcaças que seguem para o TUP de Vila do Conde.

O Terminal de Uso Privado (TUP) de Vila do Conde, recebe os grãos os grãos em caminhões ou em barcaças que em seguida são transportados em navios graneleiros do tipo post panamax que possuem capacidade de 120 toneladas e segue para os mercados consumidores internacionais.

O Corredor Logístico Sul. Visa atender o transporte de minério, grãos, fertilizantes, celulose no Brasil, Argentina, Paraguai e Uruguai.

A empresa em 31/07/2014 assinou o Contrato de Adesão no 019/2014 com a Secretaria Especial de Portos (SEP) da Presidência da República que autorizou a construção e/ou exploração da instalação portuária em Miritituba, na modalidade de Estação de Transbordo de Carga (ETC) para movimentação de granel sólido (grãos e farelo de soja).

Quanto aos dados da carga transportada em 2017 pela Hidrovia do Brasil em Miritituba, o Anuário Estatístico Aquaviário, aponta que foram transportado 2.728.059 toneladas nesta ETC. O mês com o menor volume de transporte foi janeiro com 90.119 toneladas e o mês como o maior volume transportado foi dezembro com 401.074 toneladas, conforme podemos verificar no gráfico seguinte.

Gráfico 02: Evolução da carga transportada (grãos e farelo de soja) pela Hidrovias do Brasil em Miritituba, Pará, em 2017 em toneladas

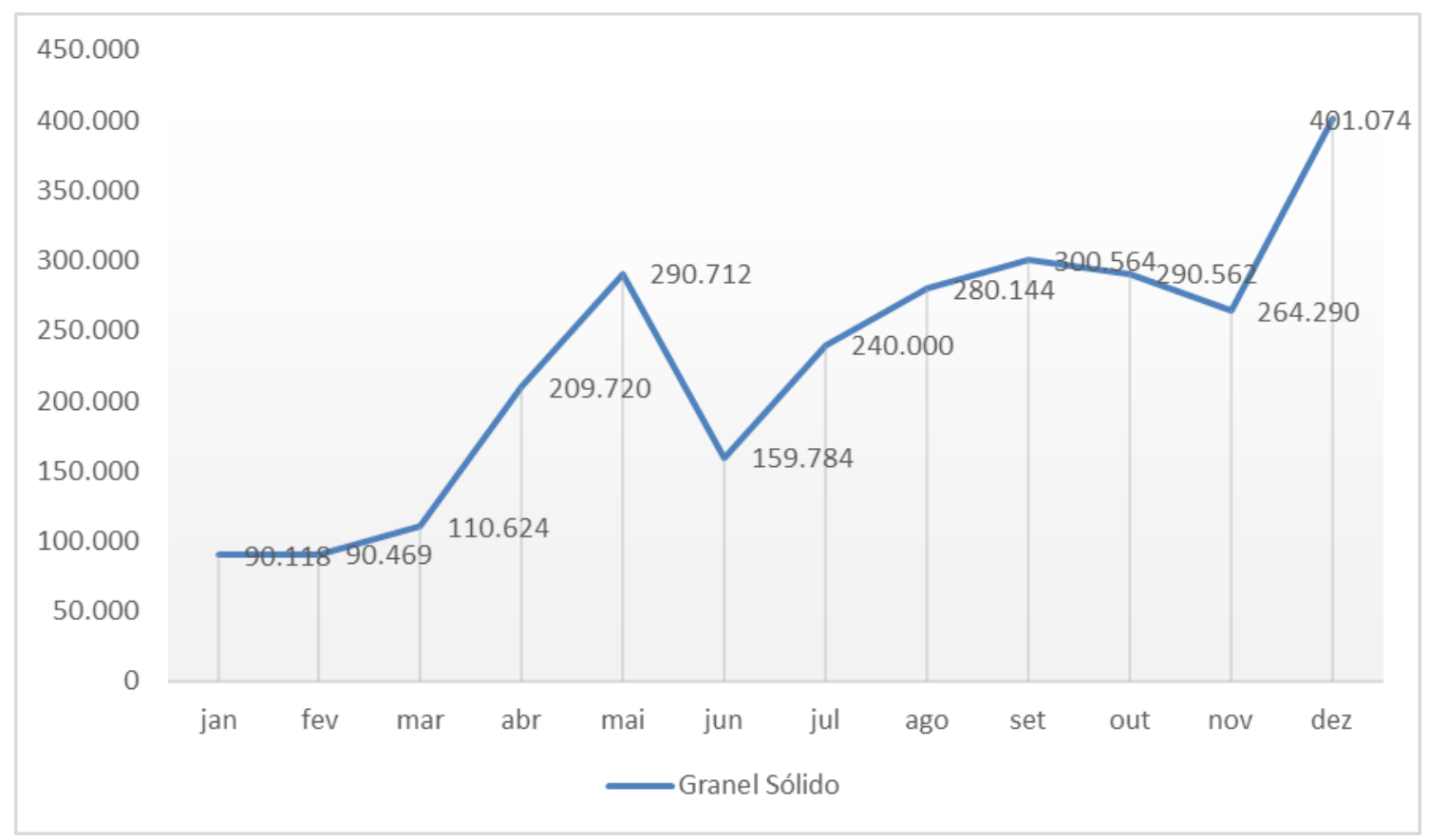

Fonte: Anuário Estatístico Aquaviário. 2019. Organizado pelo autor. 
Cianport. A Companhia Norte de Navegação e Portos S. A (Cianport) é uma Joint Venture criada em 2012, como braço logístico da Friagil que possui 32\% das ações e a Aprosoja que detém $68 \%$ da empresa. A empresa tem como objetivo o escoamento da produção de grãos da região Centro - Oeste para os portos do Arco Norte (Pará e Amapá). A empresa possui instalações na Estação de Transbordo em Miritituba, Itaituba, além de atuar em Santana, no Amapá. Em 2014 a empresa previa um investimento no Pará em Amapá de $R \$ 613$ milhões no setor de transporte de soja (VALOR ECONÔMICO, 1010612014).

Em junho de 2016 a empresa inaugurou a Estação de Transbordo de Carga (ETC Itaituba) localizada em Miritituba que contou com investimento de $R \$ 45$ milhões. Para 2017 a previsão era de exportação por esta ETC de 1, 5 milhão de toneladas de grãos. Esta estação tem capacidade para movimentar 3,5 milhões de toneladas por ano, que visa atender a produção própria de produtores da Aprosoja e da Friagil, do qual a Cianport é um importante braço logístico (ESTADO DE SÃO PAULO, 12105\2016).

A Estação de Transbordo de Carga (ETC Itaituba), está localizada em Miritituba e tem como objetivo a viabilização do escoamento de grãos pela hidrovia TapajósAmazonas até os terminais portuários de Santana, Amapá.

Os dados disponíveis pelo Anuário Estatístico Aquaviário para a ETC de Miritituba da Cianport para o ano de 2018, cobre apenas dos meses de abril a agosto, onde o mês de maio foi o mês com o menor volume transportado com 38.856 toneladas, enquanto o mês de julho foi o mês com o maior volume transportado com 177.823 toneladas. 
Gráfico 03: Evolução da carga transportada (grãos e farelo de soja) pela Cianport em Miritituba, Pará, em 2018 em toneladas

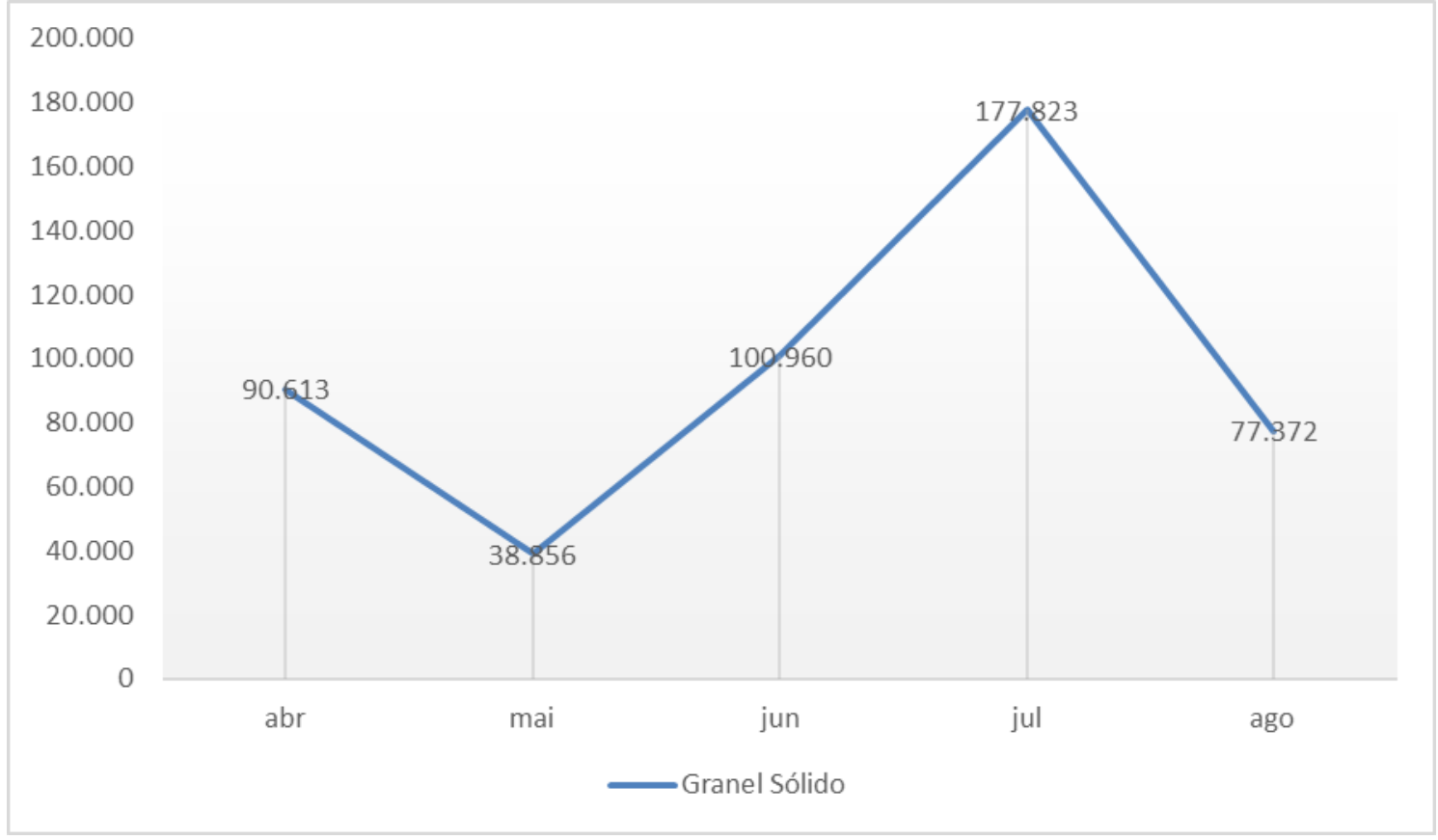

Fonte: Anuário Estatístico Aquaviário. 2019. Organizado pelo autor.

Os dados apresentados no quadro acima apresenta a quantidade de carga transportada pela empresa no período de abril a agosto de 2018 que totalizou 485.624 toneladas.

As dinâmicas a partir da instalação de Estações de Transbordo de Cargas (ETC) em Miritituba, Itaituba, Pará

A instalação de Estações de Transbordo de Cargas (ETC) pelas empresas Bunge/Amaggi, Hidrovias do Brasil, Cianport e Cargill em Miritituba promoveu uma série de transformações sócio - econômicas - territoriais como as apresentadas na sequência.

Modificação do cotidiano da população local, com a introdução de atividades estranhas a realidade local, a partir da implantação de uma racionalidade técnica portuária.

Pressão sobre os serviços públicos, por meio da chegada de novos moradores a Vila de Miritituba, o que se reflete com o aumento da procura pelos precários serviços de saúde, escola, moradia, saneamento básico existentes na localidade.

Pressão sobre as vias urbanas com a presença de carretas na vila, o que se reflete no aumento do trafego de caminhões e congestionamento na BR 163 e nas estradas de acesso as Estações de Transbordo de Cargas. 
Modificação da paisagem e do uso do solo, o que contribuiu para uma mudança da paisagem e da função da vila que surgiu como agrovila, onde as atividades primárias ligadas a pequena agricultura eram baseada na subsistência dos assentados, com a implantação das Estações de Trasbordo de Cargas, grandes objetos (SANTOS, 1995) de logística portuária passam a imprimir nova dinâmica a pequena vila localizada a margem direita do rio Tapajós.

Forte pressão na rede de postos de combustíveis para atender a demanda das corretas que chagam a Miritituba todos os dias.

Limitações a navegação, pois com a construção das Estações de Transbordo de Cargas, as empresas passam a manter um controle territorial do rio para fins de operação das atividades ligadas ao transbordo das cargas, isto implica dentre outras consequências a limitação na atividade da pesca artesanal, praticada por pequenos pescadores de Miritituba que usam o rio como território de abrigo (SANTOS, 2006).

Aumento da poeira na zona urbana de Miritituba em função do intenso trafego de carretas que transitam pelas principais ruas da vila e demais estradas de acesso as Estações de Transbordo de Cargas das empresas instaladas na vila. Tal situação tem gerado muitas reclamações de moradores que se queixam de problemas na visão.

Expansão da rede urbana de Miritituba com a criação de novos bairros como Nova Miritituba e Jardim do Éden, onde novos migrantes buscam locais de moradias e oportunidades de trabalhos nas Estações de Transborto de Cargas instaladas na vila.

A construção das Estações de Transbordo de Cargas das empresas do agronegócio da soja em Miritituba, implicou na expansão urbana por mais locais para moradia nesta localidade.

\section{Considerações Finais}

Ao longo de sua trajetória histórica, Miritituba assumiu várias funções na economia regional do Tapajós. O povoado surge em frente a cidade de Itaituba no século XVIII, sendo nestes primeiros tempos da ocupação habitada pelos colonizadores portugueses e índios Mundurukus.

Com a criação das políticas de integração nacional da década de 1970, a pequena vila torna - se uma importante agrovila do modelo da colonização dirigida pelo INCRA para a ocupação econômica - territorial da rodovia Cuiabá - Santarém. Nos lotes rurais entregues aos assentados nesta agrovila, cultivou-se por um bom 
tempo, arroz, feijão que eram usados na alimentação da família, ou vendidos no armazém da CIBRAZEM localizado na vila. A dinâmica socioeconômica nestes dois períodos históricos ocorria em função das demandas locais.

Com o avanço do asfaltamento da rodovia Cuiabá - Santarém, a partir de 2014 a localidade passou a sediar a construção de grandes objetos (SANTOS, 1995) portuários que imprimiram uma nova racionalidade na pequena vila.

Com a chegada de grandes empresas do agronegócio de soja (Bunge/Amaggi, Hidrovias do Brasil, Cianport e Cargill) na vila houve uma profunda mudança no quotidiano do moradores de Miritituba, onde uma nova racionalidade de exportação foi implantada, transformando a vila em nó do agronegócio de soja na Amazônia, responsável pela conexão do transporte de grãos pelo sistema estrada-rio.

\section{Referências}

AMAGGI. Relatório de sustentabilidade 2016. 2017.

Relatório de sustentabilidade 2017. 2018.

BARROS. Márcio Júnior Benassuly. Concepções e práticas no projeto integrado de colonização Altamira 1: o caso da agrovila vale piauiense. In. Anais do V Seminário Internacional de Geografia Agrária. Belém, 2011.

Dinâmicas territoriais do agronegócio globalizado da soja na Amazônia: o caso de Santarém (Pará). In. SILVA, Ricardo Gilson da Costa, LIMA, Luiz Augusto Pereira; CONCEIÇÃO, Francilene Sales. Amazônia: dinâmicas agrárias e territoriais contemporâneas. São Carlos, Pedro \& João Editores, 2018.

BRANDT MEIO AMBIENTE. Relatório de impacto ambiental da ETC Miritituba. Belém, Pará, 2011.

BRASIL. Ministério dos Transportes. Investimentos em portos. Brasília, DF, 2017. BUNGE. Relatório de sustentabilidade 2016. 2017.

CARDOSO, Fernando Henrique, MÜLLER, Geraldo, Amazônia: expansão do capitalismo. Brasiliense - Cebrap. São Paulo, 1977, p. 198.

CASTILLO, Ricardo. Agronegócio e logística em áreas de cerrado: expressão da agricultura científica globalizada. In. Revista da ANPEGE. V. 3, 2007.

Agricultura globalizada e logística nos cerrados brasileiros. In. Silveira, Márcio Rogério. Org. Circulação, transportes e logística: diferentes perspectivas. $1^{\mathrm{a}}$ edição. São Paulo: Outras Expressões, 2011.

DELGADO, Guilherme Costa. Do capital financeiro na agricultura a economia do agronegócio: mudanças cíclicas em meio século (1965-2012). Porto Alegre: Editora da UFRGS, 2012. 
. Economia do agronegócio (anos 2000) como pacto do poder com os donos da terra. In. Revista da Associação Brasileira de Reforma Agrária. Edição especial. Julho de 2013.

ESTADO DE SÃO PAULO. Com complexo portuário de $\mathbf{R} \$ \mathbf{7 0 0} \mathbf{m i}$, Bunge agre nova rota de exportação. São Paulo, 25/04/2014.

São Paulo. 12\05\2016.

. Miritituba encurta distância para Cianport acessar exterior.

FOLHA DE SÃO PAULO. No Pará, Dilma defende nova rota de escoamento da soja. São Paulo, 25/04/2014.

FREDERICO. Samuel. Agronegócio e dinâmica territorial brasileira no início do século XXI. In. VI Congreso Iberoamericano de Estudios Territoriales Y Ambientales. São Paulo, 2014.

IANNI, Otavio. Colonização e contra - reforma agrária na Amazônia. Petrópolis: Vozes, 1979.

IBGE, Enciclopédia dos Municípios Brasileiros. Volume XIV, Rio de Janeiro, 1957.

INCRA. Instituto Nacional de Colonização e Reforma Agrária. Altamira - 1. Brasília, 1972.

OLIVEIRA. Ariovaldo Umbelino. A Amazônia e a nova geografia da produção da soja.

Revista Terra Livre, ano 22, v. 1, n.26. Jan-Jun, 2006.

REIS, Arthur Cézar Ferreira. A política de Portugal no valle amazônico. $2^{\circ}$ ed. Belém, SECULT, 1993.

SANTOS, Milton. Os grandes projetos: sistema de ação e dinâmica espacial. In. CASTRO, Edna, MOURA, Edila A. F, MAIA, Maria Lucia. Industrialização e grandes projetos: desorganização e reorganização do espaço. Belém: Gráfisa e Editora da UFPA, 1995.

. Guerra dos lugares In. Santos, Milton. O país distorcido: o Brasil, a globalização e a cidadania. São Paulo, Publifolha, 2002.

. O retorno do território. In. SANTOS. Milton. SOUZA, M. A. de; SILVEIRA. M. L. Território: globalização e fragmentação. São Paulo: Hucitec. Anpur, 2006.

SUDAM. Superintendência do Desenvolvimento da Amazônia. Operação Amazônia (discursos). Belém, Pará, 1968.

Polamazônia Tapajós. Belém, Pará, 1976.

VALOR ECONÔMICO. Bunge estreia terminal no Pará e inicia operação pela "saída norte'. Rio de Janeiro, 25\04\2014.

VALOR ECONÔMICO. Cianport reforça aposta no norte do país. Rio de Janeiro. $10 \backslash 06 \backslash 2014$.

\section{NOTAS DE AUTOR}

\section{CONTRIBUIÇÃO DE AUTORIA}

Márcio Júnior Benassuly barros - Concepção. Coleta de dados, Análise de dados, Elaboração do manuscrito, revisão e aprovação da versão final do trabalho. 
conta com financiamento mediante alocação de carga horária na Pró-Reitoria de Pesquisa, Pós-Graduação e Inovação Tecnológica (PROPPIT) da Universidade Federal do Oeste do Pará (UFOPA). Processo: 23204.01408812018-36.

\section{CONSENTIMENTO DE USO DE IMAGEM}

Não se aplica

APROVAÇÃO DE COMITÊ DE ÉTICA EM PESQUISA

Não se aplica.

\section{CONFLITO DE INTERESSES}

Não se aplica.

\section{LICENÇA DE USO}

Este artigo está licenciado sob a Licença Creative Commons CC-BY. Com essa licença você pode compartilhar, adaptar, criar para qualquer fim, desde que atribua a autoria da obra.

\section{HISTÓRICO}

Recebido em: 30-01-2019

Aprovado em: 12-03-2019 